\title{
Treatment of Venous Thromboembolism in Special Populations with Direct Oral Anticoagulants
}

\author{
${ }^{1}$ Department of Vascular Medicine, Amsterdam UMC, University of \\ Amsterdam, Amsterdam Cardiovascular Sciences, Amsterdam, \\ The Netherlands \\ ${ }^{2}$ Section of Angiology, Center of Cardiology, University Medical \\ Center of the Johannes Gutenberg University Mainz, Germany \\ Thromb Haemost 2020;120:899-911.
}

Roisin Bavalia ${ }^{1}$ Saskia Middeldorp ${ }^{1}$ Gerhard Weisser ${ }^{2}$ Christine Espinola-Klein ${ }^{2}$

\begin{abstract}
Address for correspondence Christine Espinola-Klein, MD, Section of Angiology, Center of Cardiology, University Medical Center of the Johannes Gutenberg University Mainz, Langenbeckstrasse 1, D 55131 Mainz, Germany (e-mail: espinola@uni-mainz.de).
\end{abstract}

\begin{abstract}
Keywords

- comorbidities

- direct oral anticoagulants

- special populations

- venous thromboembolism

As a result of the successful completion of their respective phase III studies compared with vitamin $\mathrm{K}$ antagonists (VKAs), four direct oral anticoagulants (DOACs) have been approved for the treatment and secondary prevention of venous thromboembolism (VTE). These DOACs-apixaban, dabigatran, edoxaban, and rivaroxaban-have subsequently seen a steady uptake among clinicians since their approval. Despite the suitability of DOACs for a broad range of patients, they are not appropriate in certain situations, whereas in others they require additional considerations such as dose reductions. Subanalyses of phase III trials and studies on specific VTE patient populations have been conducted to evaluate the safety and efficacy of the DOACs in a broad range of settings, such as patients with renal impairment, patients with cancer, patients of childbearing potential, patients with multiple comorbidities and pediatric patients. Furthermore, many recent guidance documents from important hematological societies and other specialists have incorporated several of these developments. These documents also identify the patients for whom DOACs are not suitable and where traditional anticoagulation options such as heparins or VKAs should be considered instead. This review provides an overview of key VTE patient subgroups, the clinical evidence supporting the use of anticoagulation in these patients, and a discussion of the most appropriate approaches to their management, including considerations such as dosing, acute and extended treatment durations, and DOAC selection.
\end{abstract}

\section{Introduction}

The treatment of venous thromboembolism (VTE)-comprising deep vein thrombosis (DVT) and pulmonary embolism (PE)-has evolved with the introduction of the direct oral anticoagulants (DOACs; apixaban, dabigatran, edoxaban, and rivaroxaban), whereas previously vitamin $\mathrm{K}$ antagonists (VKAs) were the only option for oral anticoagulation. VKAs are usually administered overlapping with and followed by parenteral anticoagulation until the desired therapeutic levels are obtained (parenteral/VKA therapy). ${ }^{1}$ Dabigatran and edoxaban are indicated to be used after $\geq 5$ days of initial parenteral therapy for the acute venous thromboembolic event, whereas apixaban and rivaroxaban are eligible to be prescribed in the acute phase without prior parenteral use (-Fig. 1) ${ }^{2-5}$ Recent data from the GARFIELD-VTE registry demonstrated that nearly half of the patients with VTE enrolled between 2014 and 2017 were prescribed a DOAC, $26.8 \%$ received parenteral/VKA therapy, $17.6 \%$ a parenteral anticoagulant only, and $5.9 \%$ a VKA only. ${ }^{6}$

\section{received}

December 18, 2019

accepted

March 25, 2020
DOI https://doi.org/

10.1055/s-0040-1710314. ISSN 0340-6245. (c) 2020 Georg Thieme Verlag KG Stuttgart · New York
License terms

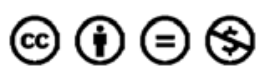




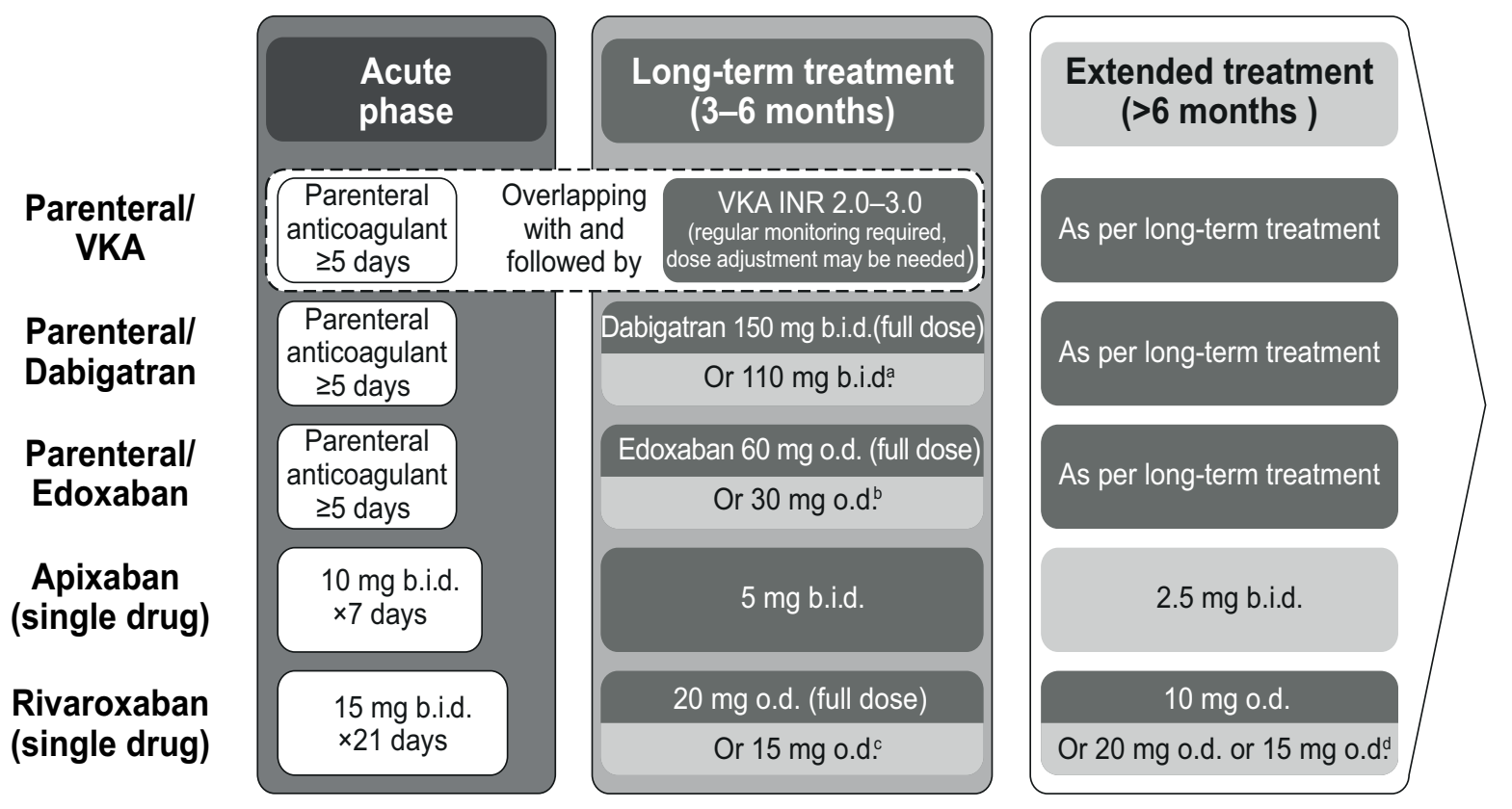

Fig. 1 Dosing schemas of oral anticoagulants approved for the treatment and/or secondary prevention of VTE. ${ }^{2-5,19}$ Figure adapted from: Thrombosis Adviser. Dosing schemas of the NOACs for VTE treatment (online). 2020. Available at: thrombosisadvisor.com/dosing-schemasNOACs-VTE/. Accessed March 13, 2020. ${ }^{a}$ Recommended for patients aged $\geq 80$ years or those receiving concomitant verapamil. To be considered for patients aged 75 to 80 years old, with $\mathrm{CrCl} 30$ to $50 \mathrm{~mL} / \mathrm{min}$, with gastritis, oesophagitis or gastroesophageal reflux, or at risk of bleeding (based on individual assessment of thromboembolic vs. bleeding risk); 'in patients with $\mathrm{CrCl} 15$ to $50 \mathrm{~mL} / \mathrm{min}$ and/or weight $\leq 60 \mathrm{~kg}$ and/or concomitant use of ciclosporin, dronedarone, erythromycin, or ketoconazole; 'in patients with $\mathrm{CrCl} 15$ to $49 \mathrm{~mL} / \mathrm{min}$ if the patients' assessed risk of bleeding outweighs that of VTE; ${ }^{d}$ when extended prevention of recurrent DVT and PE is indicated, the recommended dose is rivaroxaban $10 \mathrm{mg}$ o.d. In patients in whom the risk of recurrent DVT or PE is considered high, such as those with multiple comorbidities, or who have developed recurrent DVT or PE on extended prevention with rivaroxaban $10 \mathrm{mg}$ o.d., a dose of rivaroxaban $20 \mathrm{mg}$ o.d. should be considered (or $15 \mathrm{mg}$ o.d. in patients with $\mathrm{CrCl} 15-49 \mathrm{~mL} / \mathrm{min})$. b.i.d., twice daily; $\mathrm{CrCl}$, creatinine clearance; DVT, deep vein thrombosis; INR, international normalized ratio; NOAC, nonvitamin K oral anticoagulants; o.d., once daily; PE, pulmonary embolism; VTE, venous thromboembolism; VKA, vitamin $\mathrm{K}$ antagonist.

The increasing use of DOAC therapy coincided with recent updates to guidelines in 2016 from the American College of Chest Physicians (ACCP) ${ }^{1}$ for antithrombotic therapy for VTE and in 2019 from the European Society of Cardiology (ESC) for acute PE. ${ }^{7}$ Mainly due to the positive safety profile of the DOACs, these guidelines recommend the use of DOACs over VKA therapy in patients without cancer. ${ }^{1,7}$ These recommendations are based upon the respective phase III randomized controlled trials (RCTs) for acute VTE treatment, long-term VTE secondary prevention, ${ }^{8-13}$ and extended VTE secondary prevention. ${ }^{12,14,15}$ Furthermore, DOACs overcome some of the practical limitations associated with VKA therapy due to their more predictable pharmacological properties. ${ }^{16}$ Nonetheless, DOACs are not suitable for all patients with VTE (e.g., patients with severe renal impairment were excluded from the phase III RCTs of DOACs for VTE), and for other patient groups, dose adjustment or caution may be necessary (e.g., in patients with mild or moderate renal impairment). ${ }^{2-5}$ A growing pool of data from subanalyses of the phase III VTE treatment RCTs and new RCTs for cancer-associated thrombosis (CAT) provide an opportunity to further optimize the use of DOACs in special populations. Findings from these studies have been generally supported by evidence collected from clinical practice.
This review will discuss important questions regarding the use of DOACs in patients with VTE, including DOAC suitability, dose, and duration of treatment across important patient groups, including patients with renal impairment, cancer, or multiple comorbidities; pediatric patients; patients with high body mass index (BMI); and in circumstances of pregnancy and breastfeeding.

\section{Direct Oral Anticoagulants: An Overview}

Before discussing the use of DOACs in individual special VTE patient populations, we first consider the properties of VKAs and DOACs that might underpin drug choice and dosing decisions. Dosing strategies are outlined in - Fig. 1. Criteria for dose reductions and cautions and contraindications are outlined in - Table 1.

Apixaban, dabigatran, edoxaban, and rivaroxaban are indicated for both the treatment and secondary prevention of VTE and will, therefore, be the focus of this review. ${ }^{2-5}$ Betrixaban is an additional factor Xa inhibitor, currently only indicated for VTE prophylaxis in patients hospitalized for acute medical illness and will, ${ }^{17}$ therefore, not be discussed further. Compared with the DOACs, the inhibitory effects of 
Table 1 Dose reduction criteria and cautions and contraindications for direct oral anticoagulants approved for the treatment and/or secondary prevention of venous thromboembolism $2-5,19$

\begin{tabular}{|c|c|c|c|}
\hline DOAC & Dose reduction & Criteria for dose reduction & Cautions and contraindications \\
\hline Dabigatran & 150-110 mg b.i.d. & $\begin{array}{l}\text { Recommended for: patients aged } \\
\geq 80 \text { years or those receiving } \\
\text { concomitant verapamil. } \\
\text { To be considered for patients: aged } \\
75-80 \text { years old; with } \mathrm{CrCl} 30-50 \mathrm{~mL} / \mathrm{min} \text {; } \\
\text { with gastritis, oesophagitis or } \\
\text { gastroesophageal reflux; at risk of } \\
\text { bleeding (based on individual assessment } \\
\text { of thromboembolic versus bleeding risk). }\end{array}$ & $\begin{array}{l}\text { Contraindicated in patients using other anti- } \\
\text { coagulants or strong P-gp inhibitors, or with } \mathrm{CrCl} \\
<30 \mathrm{~mL} / \mathrm{min} \text {, active clinically relevant bleeding, } \\
\text { conditions/lesions with high bleeding risk, certain } \\
\text { hepatic diseases, prosthetic valves or who are } \\
\text { pregnant or breastfeeding. } \\
\text { Caution advised in patients at risk of bleeding or } \\
\text { undergoing surgery. } \\
\text { Not recommended in patients with hepatic } \\
\text { impairment, active cancer or using P-gp inhibitors. }\end{array}$ \\
\hline Edoxaban & $60-30$ mg o.d. & $\begin{array}{l}\mathrm{CrCl} 15-50 \mathrm{~mL} / \mathrm{min} \text { and/or weight } \leq 60 \mathrm{~kg} \\
\text { and/or concomitant use of ciclosporin, } \\
\text { dronedarone, erythromycin, or } \\
\text { ketoconazole. }\end{array}$ & 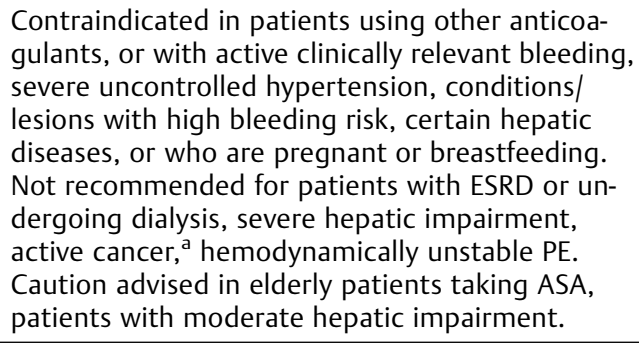 \\
\hline Apixaban & None apply & $\mathrm{N} / \mathrm{A}$ & $\begin{array}{l}\text { Contraindicated with clinically significant bleeding, } \\
\text { hepatic disease associated with coagulopathy or } \\
\text { bleeding risk, conditions/lesions with high } \\
\text { bleeding risk, or use of other anticoagulants. } \\
\text { Caution advised in elderly patients taking ASA, } \\
\text { those at risk of hemorrhage, with mild/moderate } \\
\text { hepatic impairment, } \mathrm{CrCl} 15-29 \mathrm{~mL} / \mathrm{min} \text {, or taking } \\
\text { medications that affect hemostasis. } \\
\text { Not recommended in patients with prosthetic } \\
\text { valves, hemodynamically unstable PE, active } \\
\text { cancer, } \mathrm{CrCl}<15 \mathrm{~mL} / \text { min, severe hepatic } \\
\text { impairment, using strong CYP3A4 or P-gp } \\
\text { inhibitors or inducers, who are pregnant or } \\
\text { breastfeeding, or for certain surgeries. }\end{array}$ \\
\hline Rivaroxaban & None apply & N/A & $\begin{array}{l}\text { Contraindicated in patients using other anti- } \\
\text { coagulants, or with active clinically significant } \\
\text { bleeding, conditions/lesions with high bleeding } \\
\text { risk, certain hepatic diseases, or who are pregnant } \\
\text { or breastfeeding. } \\
\text { Caution advised in patients with } \mathrm{CrCl} \\
15-29 \mathrm{~mL} / \mathrm{min} \text { or taking medicines affecting } \\
\text { hemostasis. } \\
\text { Not recommended in patients undergoing surgery, at } \\
\text { risk of hemorrhage, or with } \mathrm{CrCl}<15 \mathrm{~mL} / \mathrm{min} \text {, } \\
\text { prosthetic valves, hemodynamically unstable PE, or } \\
\text { who are treated with strong CYP3A4 or P-gP } \\
\text { inhibitors. }\end{array}$ \\
\hline
\end{tabular}

Abbreviations: ASA, acetylsalicylic acid; b.i.d., twice daily; $\mathrm{CrCl}$, creatinine clearance; CYP3A4, cytochrome P450 3A4; DOAC, direct oral anticoagulant; ESRD, end-stage renal disease; N/A, not applicable; o.d., once daily; PE, pulmonary embolism; P-gp, P glycoprotein; VTE, venous thromboembolism. aEdoxaban and rivaroxaban are now considered options for the treatment of cancer-associated thrombosis in recently published guidance (based on results from the Hokusai-VTE-Cancer and SELECT-D studies). $7,37,38,48,49,52,53$

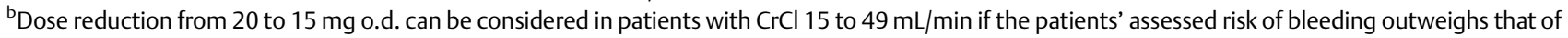
VTE.

VKAs are indirect and affect several coagulation factors. ${ }^{18}$ DOACs are also absorbed more rapidly than VKAs, reaching peak plasma concentrations between 2 and 4 hours ${ }^{2-5}$ compared with approximately 24 hours (and up to 96 hours) for VKAs. ${ }^{19}$ These properties underlie the rationale for apixaban and rivaroxaban use for acute-phase VTE treatment. Furthermore, the DOACs have short half-lives of approximately 5 to 14 hours depending on the age and renal function of a patient, ${ }^{2-5}$ compared with a half-life of approximately 40 hours for VKAs. ${ }^{19}$ A shorter half-life is advantageous in the event of overdose, bleeding or to ensure low preoperative DOAC levels in preparation for elective surgery, ${ }^{20,21}$ but may be considered a risk in circumstances of a missed dose or poor adherence to therapy. ${ }^{22}$ DOACs have demonstrated a greater consistency in dose-dependent plasma levels and have a lower potential for food-drug and drug-drug 
interactions than VKAs; as a result, no regular blood tests for anticoagulation monitoring are required with DOAC use. ${ }^{16}$ All DOACs have a degree of renal excretion as active metabolites, impacting on their use in patients with severe renal impairment $^{2-5}$; conversely, VKAs are almost entirely metabolized before urinary excretion. ${ }^{19}$ As well as differences in the pharmacokinetic profiles of DOACs and VKAs, the bleeding profiles also differ. An analysis of the phase III acute VTE trials showed that DOACs were associated with a $>50 \%$ decrease in intracranial hemorrhage or fatal bleeding events compared with VKAs. ${ }^{23}$ No differences in major gastrointestinal (GI) bleeding rates were reported in patients receiving DOACs compared with those treated with VKAs. ${ }^{23}$

In comparing the DOACs among themselves, apixaban, dabigatran, and edoxaban can be taken with or without food, whereas the higher (15 mg once daily [o.d.] and $20 \mathrm{mg}$ o.d.) doses of rivaroxaban should be taken with food. This is because food increases the bioavailability of rivaroxaban at higher doses and facilitates full resorption. In terms of drug interactions, all DOACs are substrates of ATP-binding cassette transporters such as P-glycoprotein, and rivaroxaban and apixaban are also metabolized by the cytochrome P450 3A4 pathway. ${ }^{2-5}$ Renal excretion as active metabolites ranges from $27 \%$ for apixaban to $85 \%$ for dabigatran to approximately onethird for edoxaban and rivaroxaban. Although the DOACs all have similar pharmacokinetic properties, apixaban and dabigatran are dosed twice daily (b.i.d.) and edoxaban and rivaroxaban o.d. for long-term and extended secondary prevention of VTE. ${ }^{2-5,20}$ As discussed previously, apixaban and rivaroxaban are approved for acute-phase VTE treatment without prior parenteral anticoagulation; to replace the use of a parenteral therapy an intensified b.i.d. dosing regimen applies. $^{2,5}$ The observational XALIA study demonstrated that in clinical practice the majority of patients with DVT without PE (89\%) and with PE (74\%) treated with rivaroxaban received no more than 48 hours of parenteral therapy before use. ${ }^{24}$ Conversely, dabigatran and edoxaban should follow at least 5 days of initial parenteral therapy for acute VTE, ${ }^{3,4}$ based on the design of their respective phase III RCTs (RE-COVER and Hokusai-VTE).$^{10,11}$ Reversal agents are now available for dabigatran (idarucizumab) ${ }^{25}$ and the direct and indirect Factor Xa inhibitors (andexanet alfa; approved for use in the United States, granted a conditional marketing authorization in the EU as of 1 March 2019). ${ }^{26,27}$

\section{Direct Oral Anticoagulants in Special Patient Populations: Clinical Evidence and Practical Considerations}

\section{Patients with Renal Impairment}

Renal impairment is a frequently encountered comorbidity in patients with VTE. For example, of 5,710 hospitalized patients with VTE in a study based in Germany, $>40 \%$ had at least moderate renal impairment. ${ }^{28}$ In the GARFIELD-VTE registry, which enrolled 10,685 patients with VTE from a diverse range of care settings, $4.6 \%$ of patients had severe (creatinine clearance $[\mathrm{CrCl}]<\mathrm{mL} / \mathrm{min}$ ), and $15.7 \%$ had moderate $(\mathrm{CrCl}: 30-59 \mathrm{~mL} / \mathrm{min})$ renal impairment. ${ }^{6}$ Both the risk of VTE and bleeding while receiving an anticoagulant increases with declining renal function. ${ }^{29,30}$ In the control (parenteral/VKA therapy) arm of a pooled analysis of data from the EINSTEIN DVT and EINSTEIN PE studies, the risk of recurrent VTE was $1.9 \%$ in patients with normal renal function $(\mathrm{CrCl} \geq 80 \mathrm{~mL} / \mathrm{min})$ versus $3.2 \%$ in patients with moderate renal impairment $(\mathrm{CrCl}: 30-49 \mathrm{~mL} / \mathrm{min}) .{ }^{31}$ On the other hand, impaired renal function is also a risk factor for major bleeding, as demonstrated in the RIETE registry. The RIETE registry is an ongoing prospective registry of $>10,000$ patients with objectively confirmed symptomatic acute VTE. In an analysis of results up to March 2005 (at which point the registry included $>10,000$ patients), impaired renal function was associated with an increased risk of major bleeding ( $5.4 \%$ with a $\mathrm{CrCl}<30 \mathrm{~mL} / \mathrm{min}$ vs. $1.0 \%$ with a $\mathrm{CrCl}>60 \mathrm{~mL} / \mathrm{min}$; odds ratio [OR]: $5.6,95 \%$ confidence interval $[\mathrm{CI}]: 3.7-8.4 ; p<0.001)$ and fatal bleeding $(1.2 \%$ with a $\mathrm{CrCl}<30 \mathrm{~mL} / \mathrm{min}$ vs. $0.2 \%$ with a $\mathrm{CrCl}>60 \mathrm{~mL} / \mathrm{min}$; OR: 6.5, 95\% CI: 2.7-16.0; $p<0.001$ ) compared with normal renal function. The registry also described an increased risk of fatal $\mathrm{PE}(6.6 \%$ with a $\mathrm{CrCl}<30 \mathrm{~mL} / \mathrm{min}$ vs. $1.0 \%$ with a $\mathrm{CrCl}>60 \mathrm{~mL} / \mathrm{min}$; OR: 7.2, 95\% CI: 4.9-11.0; $p<0.001) .{ }^{32}$

The safety and effectiveness of DOACs in patients with renal impairment ranging from moderate to mild (but not severe) has been evaluated through RCTs, and data collected from clinical practice. The DOAC phase III VTE treatment trials included more than 7,000 patients with impaired renal function ( $\sim 5-8 \%$ had moderate [CrCl: $30-49 \mathrm{~mL} / \mathrm{min}]$ and approximately 20 to $25 \%$ mild [CrCl: $50-79 \mathrm{~mL} / \mathrm{min}$ ] renal impairment). Severe renal impairment $(\mathrm{CrCl}<30 \mathrm{~mL} / \mathrm{min}$ [except in the AMPLIFY trial of apixaban, which used a threshold of $\mathrm{CrCl}<25 \mathrm{~mL} / \mathrm{min}$ ]) was an exclusion criterion across these studies. ${ }^{8,11,31,33}$ As a result, patients with severe renal impairment made up $<1 \%$ of the DOAC study populations, ${ }^{8,11,31}$ and in a pooled analysis of dabigatran in the RE-COVER and RECOVER II studies, such patients were excluded entirely. ${ }^{33}$

Subgroup analyses of outcomes according to renal function suggest that DOACs are effective and at least as safe as enoxaparin/VKA therapy for the treatment of VTE in patients with mild-to-moderate renal impairment. In a meta-analysis of these data, the risk of recurrent VTE or VTE-related death with DOAC (apixaban, dabigatran, edoxaban, or rivaroxaban) therapy was similar to enoxaparin/VKA therapy in patients with a $\mathrm{CrCl} \geq 50 \mathrm{~mL} / \mathrm{min}$ and a $\mathrm{CrCl}$ of 30 to $49 \mathrm{~mL} / \mathrm{min}$, whereas the risk of major bleeding was lower with DOAC therapy versus enoxaparin/VKA in both subgroups. ${ }^{23}$ In another meta-analysis, the observed reduction in the risk of bleeding with DOAC versus enoxaparin/VKA therapy in patients with a $\mathrm{CrCl} \leq 50 \mathrm{~mL} / \mathrm{min}$ reached significance with rivaroxaban, and was observed as a nonsignificant trend with apixaban. The risk appeared more equal between treatment arms with dabigatran (-Fig. 2). ${ }^{34}$

Because drug exposure can increase with declining renal function in accordance with the proportion of the agent that is excreted renally, ${ }^{35}$ careful consideration of anticoagulant choice is important. Furthermore, because renal function can decline over time-particularly in elderly patients and those taking multiple medications-regular assessment of renal 


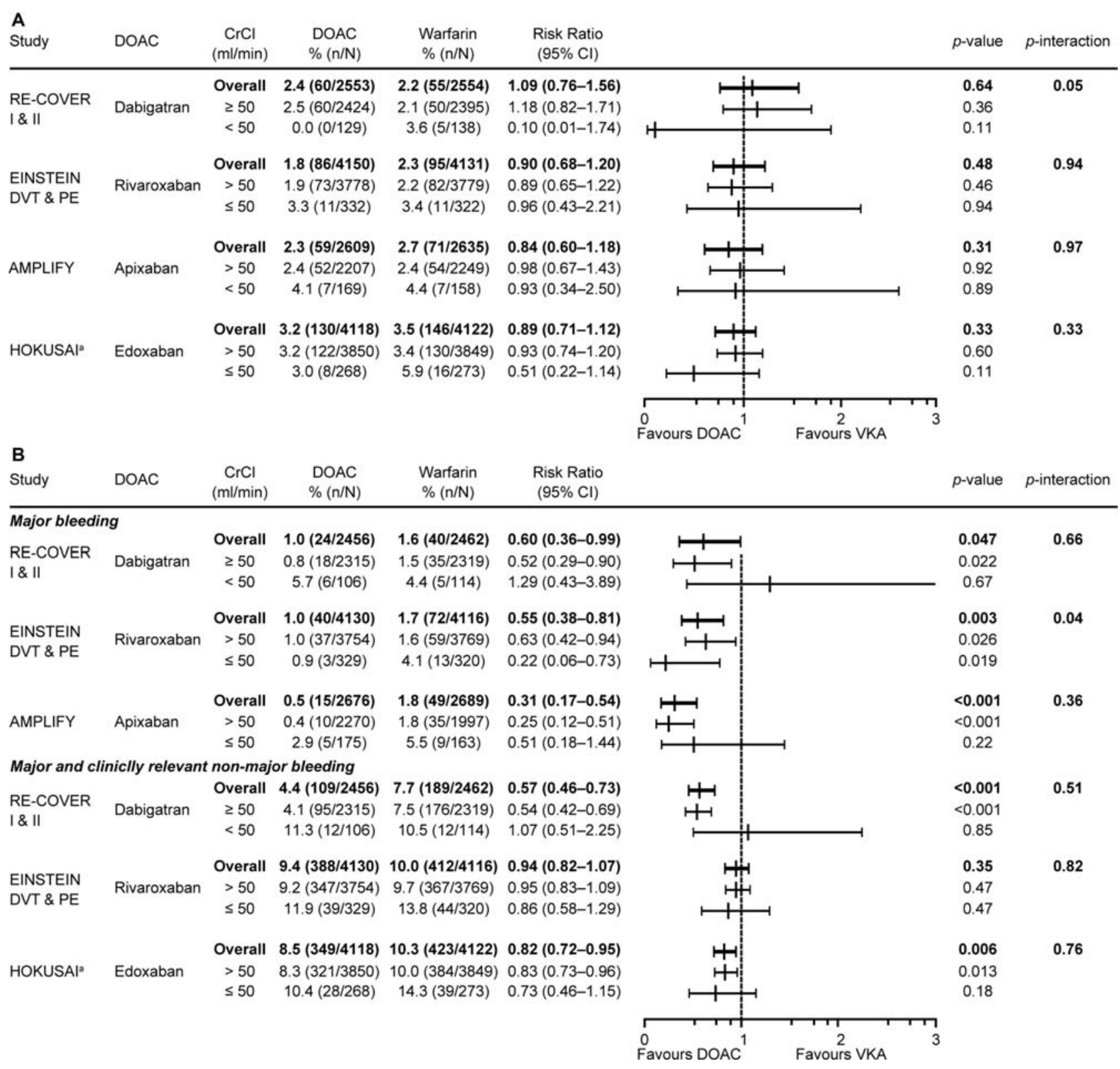

Fig. 2 Rates of (A) recurrent VTE and (B) major bleeding and major plus clinically relevant nonmajor bleeding ${ }^{\mathrm{a}}$ with DOAC versus warfarin therapy in the phase III DOAC for VTE treatment trials. ${ }^{34, a}$ Data for major bleeding in the Hokusai-VTE trial and major plus clinically relevant nonmajor bleeding in the AMPLIFY trial were not reported in the original studies. Figure adapted from Geldhof et al. ${ }^{34} \mathrm{Cl}$, confidence interval; $\mathrm{CrCl}$, creatinine clearance; DOAC, direct oral anticoagulant; VKA, vitamin K antagonist; VTE, venous thromboembolism.

function during the use of anticoagulation therapy is necessary. ${ }^{36}$ Of all the DOACs, dabigatran has the highest degree of renal elimination as an active metabolite and apixaban the lowest. However, the use of DOACs is only contraindicated in cases of severe renal impairment $(\mathrm{CrCl}<15 \mathrm{~mL} / \mathrm{min}$ or $\mathrm{CrCl}<30 \mathrm{~mL} / \mathrm{min}$ for dabigatran); for less severe cases, cautions and dose reductions sometimes apply (- Table 1). ${ }^{2-5,19}$ With regard to VKAs, some evidence suggests that they are associated with accelerated progression in chronic kidney disease, possibly because of renal vascular calcification. ${ }^{37}$

\section{Patients with Cancer}

Cancer and its treatments are associated with a hypercoagulable state and are well-known risk factors for VTE (com- monly referred to as cancer associated thrombosis [CAT]). Extended periods of anticoagulation therapy of at least 6 months are recommended for patients with CAT. ${ }^{7,38,39}$ Until recently, low molecular weight heparin (LMWH) was the preferred therapy based on superior efficacy and/or safety compared with VKAs in the oncology setting. ${ }^{40-43}$ Advantages of LMWH therapy for CAT include reliability in patients who have difficulty with oral therapy (e.g., those suffering from nausea/vomiting), ${ }^{1}$ and there has been some experience gained in managing LMWH dosing in circumstances of thrombocytopenia (a complication often secondary to chemotherapy). ${ }^{1,44}$ However, long-term persistence with LMWH may be challenging for some patients because of the burden and discomfort of daily subcutaneous injections; 
furthermore, LMWHs are costly, with reimbursement an issue in some countries. ${ }^{45}$ Indeed, low persistence with LMWH therapy and frequent use of oral alternatives (namely VKAs and rivaroxaban) have been observed in clinical practice. $^{46-48}$ This warranted the evaluation of DOACs versus LMWH for the treatment of CAT.

The phase III Hokusai-VTE-Cancer study ${ }^{49,50}$ of edoxaban versus dalteparin and the randomized SELECT-D pilot study ${ }^{51}$ of rivaroxaban versus dalteparin were the first cancer-population-specific randomized trials for DOACs in patients with CAT, and the first to compare DOACs with LMWH in this setting. The study designs and results are summarized in - Table 2 . As per the CLOT study design, ${ }^{41}$ the dalteparin dose was reduced after 4 weeks from 200 to $150 \mathrm{IU} / \mathrm{kg} /$ day in both studies. Therefore, full-dose anticoagulation with edoxaban or rivaroxaban was compared with reduced-dose dalteparin. ${ }^{49,51}$ In Hokusai-VTECancer, edoxaban was noninferior to dalteparin for the composite outcome of recurrent VTE and major bleeding (12.8 vs. 13.5\%; hazard ratio [HR]: 0.97, 95\% CI: 0.70-1.36; $p=0.006)$. Whereas the risk of recurrent VTE was significantly lower with edoxaban versus dalteparin, the risk of major bleeding was significantly higher (- Table 2 ). In line with previous observational data, ${ }^{46-48}$ patients randomized to the edoxaban arm continued therapy for significantly longer than patients randomized to LMWH (211 vs. 184 days; $p=0.01$ ); $14.9 \%$ of patients who discontinued dalteparin did so because of the inconvenience of dosing (compared with $4.0 \%$ of patients who received edoxaban). A sensitivity analysis demonstrated that the longer duration of edoxaban versus dalteparin therapy did not heavily influence efficacy outcomes. ${ }^{49}$ In the SELECT-D pilot study, rivaroxaban was associated with a lower rate of recurrent VTE at 6 months but a higher rate of major bleeding and clinically relevant nonmajor bleeding (CRNM; - Table 2). However, the study was not powered to test efficacy and safety hypotheses. ${ }^{51}$ One potential reason for the higher rates of major bleeding observed with DOACs compared with dalteparin, in both Hokusai-VTE-Cancer and SELECT-D, is the reduction in dalteparin dose after 4 weeks. In both studies, the majority of major bleeding events were GI bleeding, which were largely responsible for the higher rates of bleeding associated with DOAC versus dalteparin therapy (-Table 2). Furthermore, GI bleeding events were most frequent in patients with GI tract tumors. ${ }^{49,51}$ In SELECT-D, only 19 patients with cancer of the esophagus or gastroesophageal tract were enrolled, with these cancer types excluded from enrolment part way through the study following an interim safety analysis, in which a nonsignificant increase in major bleeding with rivaroxaban versus dalteparin was demonstrated. ${ }^{51}$ Results from the ADAM-VTE trial, an investigator-led, randomized, open-label study of apixaban versus dalteparin for the treatment of CAT $(n=300)$ demonstrated a very low incidence of major bleeding in both treatment groups ( 0 in the apixaban arm vs. $1.4 \%$ in the dalteparin arm; HR not estimable; $p=0.14)$ and comparable incidences of major and CRNM bleeding events in both groups (6.2\% in the apixaban arm vs. $6.3 \%$ in the dalteparin arm; HR: $0.93,95 \% \mathrm{CI}: 0.43-2.02$; $p=0.88$ ). Of note, this study included fewer patients with upper GI malignancies than the Hokusai-VTE-Cancer and
SELECT-D trials. VTE recurrence was, as observed in the Hokusai-VTE-Cancer and SELECT-D trials, lower in the DOAC arm (apixaban) compared with the dalteparin arm (0.7 vs. 6.3\%, respectively; HR: 0.099, 95\% CI: 0.013-0.780; $p=0.03$ ). All-cause mortality was also low in both treatment arms (16\% with apixaban vs. $11 \%$ with dalteparin; HR: $0.40,95 \%$ CI: $0.82-$ 2.43; $p=0.31$ ); the reasons for these low event rates are unclear and cannot be explained by patient characteristics. ${ }^{52}$

Considering the latest data, the 2019 update of guidelines from the American Society of Clinical Oncology (ASCO) recommend that a parenteral anticoagulant (LMWH, unfractionated heparin or fondaparinux) or rivaroxaban is used for the initial treatment of CAT and that LMWH, edoxaban or rivaroxaban is used for long-term therapy. The guidelines also advise caution with DOACs in settings with a high risk of mucosal bleeding, including in patients with GI and genitourinary malignancies and note the potential for drug-drug interactions should be checked before use. ${ }^{38}$ The 2019 update to the ESC guidelines on the management of acute PE recommend that LMWHs are considered for the first 6 months over VKAs, and that edoxaban and rivaroxaban can be considered as alternatives to LMWH in patients without GI cancer. ${ }^{7}$ Recently published guidance also suggests edoxaban and rivaroxaban (International Society on Thrombosis and Haemostasis [ISTH]; International Initiative on Thrombosis and Cancer [ITAC]), ${ }^{39,53}$ or edoxaban preferred over rivaroxaban (National Comprehensive Cancer Network) ${ }^{54}$ over LMWH for selected patients, with some but not all patients with cancer suitable for DOAC therapy. ${ }^{39,53,54}$ These guideline and guidance documents also note that patient preferences should be considered when deciding upon the anticoagulant and duration of therapy, and that final treatment recommendations should be made after shared decision-making with patients. ${ }^{7,38,39,53,54}$ In the noninterventional, single-arm COSIMO study, patients with active cancer and CAT who switched from $\geq 4$ weeks of traditional anticoagulants (predominately LMWH) to rivaroxaban reported an increase in treatment satisfaction, noting in particular a significant decrease in burdens associated with anticoagulation between baseline (the point of change) and week 4 , which persisted at months 3 and $6 .{ }^{55}$ A discrete choice experiment conducted during the study demonstrated that, outside of effectiveness and safety, route of administration was the strongest attribute for driving treatment decision-making, with patients demonstrating a strong preference for oral over injectable anticoagulants. ${ }^{56}$

Although the evidence base to date generally supports the use of DOACs for the treatment of CAT, increased granularity of data is required, that is, according to cancer type/stage and systemic oncological therapy is needed. Additional data on the use of DOACs for the treatment of CAT will come from the ongoing phase III RCT CARAVAGGIO ${ }^{57}$ for apixaban versus dalteparin and subanalyses of the preexisting data, as well as additional studies for rivaroxaban in CAT (the phase III CASTA-DIVA ${ }^{58}$ and CONKO-011 ${ }^{59}$ studies).

DOACs are also under investigation for the primary prevention of CAT in ambulatory cancer patients receiving systemic cancer therapies and results from the AVERT study for apixaban, and the CASSINI study for rivaroxaban (both placebo-controlled 


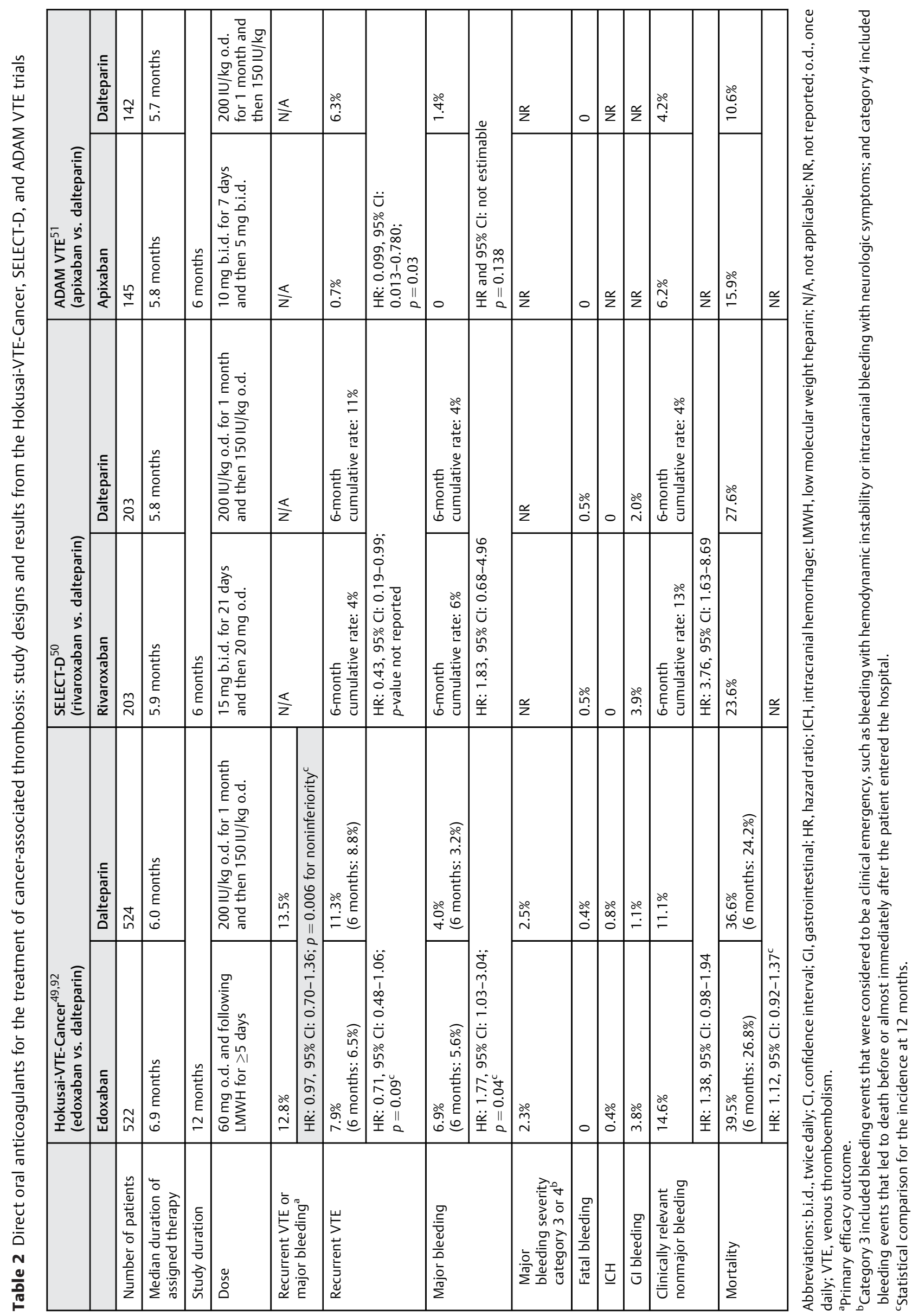


randomized trials) are now published. ${ }^{60,61}$ In the AVERT study, apixaban significantly reduced the risk of VTE (HR: $0.41,95 \% \mathrm{CI}$ : 0.26-0.65) and increased the risk of major bleeding compared with placebo (HR: $2.00,95 \%$ CI: 1.01-3.95) in ambulatory patients with cancer with an intermediate-to-high risk of VTE (Khorana's score $\geq 2$ ) who were initiating chemotherapy. ${ }^{61}$ The CASSINI study, in which ambulatory patients with cancer and an intermediate-to-high risk of VTE (Khorana's score $\geq 2$ ) received rivaroxaban, showed similar results, with the risk of the composite of VTE and VTE-related death (HR: 0.66, 95\% CI: 0.401.09 ) and of major bleeding (HR: $1.96,95 \% \mathrm{CI}: 0.59-6.49$ ) versus those receiving placebo, with both differences not reaching statistical significance. ${ }^{60}$ Thromboprophylaxis is not routinely recommended in ambulatory patients with cancer. ${ }^{38,39,54}$ However, for patients receiving systemic cancer therapy who are at an intermediate to high risk of VTE (i.e., a Khorana's risk score $\geq 2$ ), and in the absence of significant risk factors for bleeding, the 2019 updates to the ASCO guidelines and ITAC guidance for cancer-associated VTE endorse the use of apixaban or rivaroxaban for thromboprophylaxis. The ASCO guidelines also endorse the use of LMWH in this setting, whereas ITAC guidance only recommends it in patients with locally advanced or metastatic pancreatic cancer. ${ }^{38,39}$

\section{The Multimorbid Patient}

Patients with VTE often have a range of factors (e.g., old age and extremes in body weight) and comorbidities (e.g., cancer and renal disease) associated with an increased risk of VTE recurrence and/or bleeding with anticoagulation therapy. For example, in the PREFER in VTE registry (which enrolled patients with VTE between 2013 and 2015), the mean age was 60.8 years, the average BMI $27.9 \mathrm{~kg} / \mathrm{m}^{2}, 6.2 \%$ of patients had renal disease, and 53.3\% active cancer. ${ }^{62}$ Atrial fibrillation $(\mathrm{AF})$ and cardiovascular (CV) disease (such as coronary artery disease and peripheral artery disease and $\mathrm{CV}$ risk factors such as hypertension) are also highly prevalent in patients with VTE. For example, of patients enrolled in the PREFER in VTE registry, 3.5\% had a history of AF and $45 \%$ had CV disease (excluding hypertension), whereas hypertension alone was present in $42.3 \%$ of patients. ${ }^{62}$ Studies have demonstrated a link between these thromboembolic diseases, reflecting shared underlying risk factors. ${ }^{63,64}$ The presence of multiple indications for antithrombotic use complicates disease management because of differences in recommended drug choice and dosing regimens. Decisions in this regard may need to be based on clinical judgement and the expertise of a multidisciplinary team.

The relative efficacy and safety of DOAC versus VKA therapy across relevant high-risk subgroups has been demonstrated in the phase III DOAC VTE treatment studies; a pooled analysis of such data are shown in - Table 3. ${ }^{23}$ The EINSTEIN DVT and EINSTEIN PE studies for rivaroxaban and Hokusai-VTE for edoxaban considered multimorbid patients in subgroup analyses. ${ }^{65,66}$ In the pooled analysis of the EINSTEIN DVT and EINSTEIN PE, "fragile" patients were a group defined by the presence of $\geq 1$ of the following criteria: age $>75$ years, $\mathrm{CrCl}<50 \mathrm{~mL} / \mathrm{min}$ or low body weight $\leq 50 \mathrm{~kg}$. As expected, rates of recurrent VTE and bleeding were higher in the "fragile" $(n=1,573)$ versus "nonfragile" ( $n=6,709)$ populations. Whereas rates of recurrent VTE with rivaroxaban versus enoxaparin/VKA treatment in the "fragile" subgroup were similar, there was a statistically significant difference in rates of major bleeding favoring rivaroxaban over enoxaparin/VKA use (1.3 vs. $4.5 \%$; HR: $0.27,95 \%$ CI: 0.13-0.54). Overall, the composite outcome of symptomatic recurrent VTE and major bleeding was significantly lower with rivaroxaban versus enoxaparin/VKA in the "fragile" patient subgroup (4.6 vs. $8.4 \%$; HR: $0.51,95 \% \mathrm{CI}$ : 0.34-0.77). ${ }^{65}$ In a subanalysis of the Hokusai-VTE data, the impact of age, number of comorbidities and concomitant medications on efficacy, and safety outcomes was evaluated. In the warfarin group, but not in the edoxaban group, the risk of recurrent VTE increased with advancing age, increasing number of comorbidities and increasing number of drugs used. Indeed, edoxaban was more effective than warfarin in patients $\geq 80$ years old with more than two comorbidities or receiving more than five concomitant medications (HR: 0.63 , $95 \% \mathrm{CI}: 0.41-0.96)$. In the same subgroup, the relative safety of edoxaban versus warfarin (in terms of major bleeding and CRNM bleeding) was well maintained despite the elevated risk of bleeding in both treatment arms. Overall, the net clinical benefit favored edoxaban use across the separate components of this subgroup. ${ }^{66}$

\section{Other Patient Groups}

\section{Pediatric Patients}

Although the incidence of VTE in children is approximately 100 times lower than the incidence in adult patients, there is an increasing need for improved options for anticoagulation in the pediatric population. For example, anticoagulation might be needed in pediatric cases of VTE caused by surgery or illness such as cancer, in cases of severe thrombophilia or in female pediatric patients with newly prescribed oral contraception. However, based on challenges associated with enrolment and retention of younger patients in clinical trials and the collection of blood samples for monitoring purposes, there is a paucity of data supporting the use of anticoagulants in this patient population. Current guidelines are mainly based on extrapolation from trials in adults. Currently, none of the DOACs are approved for use in pediatric patients; however, challenges associated with intravenous/subcutaneous delivery of anticoagulants in this population warranted further study of oral options. ${ }^{67-69}$

Phase $\mathrm{I} / \mathrm{II}$ trials for dabigatran ${ }^{70-72}$ and rivaroxaban ${ }^{73}$ established suitable age-/body weight-adjusted dosing regimens for these agents for pediatric use, and both DOACs were well tolerated in these studies. Dabigatran and rivaroxaban are now in phase IIb/III testing in open-label trials for the treatment of VTE in pediatric patients.

The phase IIb/III DIVERSITY study evaluated the efficacy and safety of dabigatran following initial LMWH or UFH therapy in pediatric patients who are expected to require anticoagulation for $\geq 3$ months. Initial dosing was determined using an algorithm and dabigatran administered b.i.d. as capsules, pellets or in liquid form according to the patient's age. ${ }^{74}$ An interim analysis in approximately 220 patients demonstrated similar 
Table 3 Recurrent venous thromboembolism and major bleeding with direct oral anticoagulants versus vitamin $\mathrm{K}$ antagonist use across important patient subgroups in the phase III direct oral anticoagulants for venous thromboembolism treatment trials ${ }^{23}$

\begin{tabular}{|c|c|c|c|c|}
\hline & $\begin{array}{l}\text { Pooled DOAC } \\
\mathrm{n} / \mathrm{N}(\%)\end{array}$ & $\begin{array}{l}\text { Pooled VKA } \\
\text { n/N (\%) }\end{array}$ & RR $(95 \% \mathrm{Cl})$ & $p$-Value \\
\hline \multicolumn{5}{|c|}{ First recurrent VTE or VTE-related deaths } \\
\hline \multicolumn{5}{|l|}{ Index event } \\
\hline $\mathrm{PE} \pm \mathrm{DVT}$ & $136 / 5,764(2.4)$ & $153 / 5,775(2.6)$ & $0.89(0.71-1.12)$ & 0.32 \\
\hline DVT only & 199/7,655 (2.6) & $213 / 7,654(2.8)$ & $0.93(0.77-1.13)$ & 0.49 \\
\hline \multicolumn{5}{|c|}{ Body weight $(\mathrm{kg})$} \\
\hline$<100$ & $57 / 2,146(2.7)$ & $62 / 2,157$ (2.9) & $0.90(0.77-1.06)$ & 0.22 \\
\hline$\geq 100$ & $278 / 11,354(2.4)$ & $305 / 11,262(2.7)$ & $0.92(0.64-1.32)$ & 0.65 \\
\hline \multicolumn{5}{|c|}{$\mathrm{CrCl}(\mathrm{mL} / \mathrm{min})$} \\
\hline $30-49$ & $26 / 898(2.9)$ & 39/891 (4.4) & $0.70(0.43-1.15)$ & 0.16 \\
\hline$\geq 50$ & $307 / 12,248(2.5)$ & $316 / 12,282(2.6)$ & $0.97(0.83-1.14)$ & 0.74 \\
\hline \multicolumn{5}{|l|}{ Age $(y)$} \\
\hline$<75$ & $296 / 11,572(2.6)$ & 299/11,635 (2.6) & $0.99(0.85-1.17)$ & 0.95 \\
\hline$\geq 75$ & $39 / 1,858(2.1)$ & $68 / 1,807(3.8)$ & $0.56(0.38-0.82)$ & 0.003 \\
\hline \multicolumn{5}{|l|}{ Cancer } \\
\hline No & $308 / 12,625(2.4)$ & $321 / 12,666(2.5)$ & $0.96(0.82-1.12)$ & 0.63 \\
\hline Yes & $27 / 805$ (3.4) & $46 / 776$ (5.9) & $0.57(0.36-0.91)$ & 0.02 \\
\hline \multicolumn{5}{|c|}{ Major bleeding } \\
\hline \multicolumn{5}{|c|}{$\mathrm{CrCl}(\mathrm{mL} / \mathrm{min})$} \\
\hline $30-49$ & $16 / 878(1.8)$ & $33 / 870(3.8)$ & $0.51(0.26-0.99)$ & 0.05 \\
\hline$\geq 50$ & $132 / 12,329(1.1)$ & $200 / 12,358(1.6)$ & $0.60(0.40-0.90)$ & 0.01 \\
\hline \multicolumn{5}{|l|}{ Age (y) } \\
\hline$<75$ & $109 / 11,633(0.9)$ & $165 / 11,681(1.4)$ & $0.62(0.45-0.84)$ & 0.002 \\
\hline$\geq 75$ & $37 / 1,844(2.0)$ & $73 / 1,800(4.1)$ & $0.49(0.25-0.96)$ & 0.04 \\
\hline \multicolumn{5}{|l|}{ Cancer } \\
\hline No & $120 / 12,624(1.0)$ & 204/12,705 (1.6) & $0.59(0.41-0.83)$ & 0.003 \\
\hline Yes & 23/806 (2.9) & 29/776 (3.7) & $0.77(0.44-1.33)$ & 0.35 \\
\hline
\end{tabular}

Abbreviations: $\mathrm{Cl}$, confidence interval; $\mathrm{CrCl}$, creatinine clearance; DOAC, direct oral anticoagulant; DVT, deep vein thrombosis; PE, pulmonary embolism; RR, relative risk; VKA, vitamin K antagonist; VTE, venous thromboembolism.

efficacy and safety of dabigatran and standard of care, and confirmed the pharmacokinetic/pharmacodynamic profile of weight-adjusted dabigatran in children. ${ }^{75}$ In addition, an interim analysis of a single-arm, prospective cohort, phase III study demonstrated a favorable safety profile of dabigatran used for up to 12 months in approximately 200 children aged 0 to $<18$ years who required anticoagulation for the secondary prevention of VTE and with a persistent risk factor for VTE. ${ }^{76,77}$

The phase III EINSTEIN Junior trial evaluated rivaroxaban (20 mg o.d. equivalent adjusted according to body weight following at least 5 days of initial heparin therapy) versus standard of care anticoagulation therapy for the treatment of acute VTE in approximately 500 children and neonates. ${ }^{78}$ The risks of recurrent VTE (occurring in 4/335 [1.2\%] of patients receiving rivaroxaban and in 5/165 [3.0\%] receiving standard of care) and major bleeding events (occurring in 0/329 [0.0\%] of patients receiving rivaroxaban and 2/162 [1.2\%] receiving standard of care) were low and similar in patients receiving rivaroxaban versus those receiving standard of care, and the results of the study were similar to those previously reported for adults. ${ }^{79}$ Clinical data on the use of apixaban and edoxaban in pediatric patients are yet to be published, but studies are ongoing. ${ }^{80-82}$

Female Patients: Pregnancy, Fertility, and Breastfeeding Patients who were pregnant or breastfeeding were excluded from the DOAC VTE treatment trials, $, 8,9,11-13$ as well as trials for other thromboembolic indications. Based on this, and preclinical data, pregnancy and breastfeeding are contraindications for edoxaban and rivaroxaban use $e^{4,5}$; apixaban and dabigatran are also not recommended in these circumstances. ${ }^{2,3}$ Reproductive toxicity has been demonstrated in animal studies evaluating dabigatran, edoxaban, and rivaroxaban; all three DOACs affected fetal development and dabigatran had negative impacts on female fertility. ${ }^{3-5}$ For apixaban, animal studies did not indicate direct or indirect harmful effects on 
pregnancy or fertility, but there is a lack of clinical data for human use. ${ }^{2}$ It is unknown whether DOACs or their metabolites are excreted in human milk, but excretion has been demonstrated in animal studies for all four DOACs. Therefore, a risk to infants cannot be excluded. ${ }^{2-5}$ Currently, $\mathrm{LMWH}$ is the preferred option in this clinical setting. Guidance on the management of DOACs during pregnancy has been issued by the Scientific and Standardization Committee (SSC) of the ISTH and $\mathrm{ASH}^{83,84}$ The SSC of the ISTH advises that all women of childbearing potential should receive documented counselling before initiation of DOACs, and there should be an emphasis on avoiding pregnancy while on a DOAC via implementing adequate and appropriate contraceptive methods. In those patients wishing to become pregnant, the guidance advises to switch from a DOAC to another anticoagulant prior to conception. The advised anticoagulant choices in this situation are VKAs (switching to LMWH as soon as possible when pregnant and before 6 weeks of gestation), or LMWH, taking into account that LMWH may necessitate a prolonged period of subcutaneous injections until pregnancy occurs. ${ }^{83}$ Use of LMWH during pregnancy (in preference to UFH) is also recommended by the ASH guidelines, while DOACs are not considered in this setting due to concerns over these agents crossing the placenta and a lack of clear evidence on reproductive toxicity ${ }^{84}$ In cases of unintentional conception while receiving DOAC therapy, the SSC of the ISTH recommend that the DOAC is discontinued immediately and the patient is initiated on LMWH. However, inadvertent DOAC exposure after conception should not to be considered in itself as medical grounds for abortion although early obstetric review and fetal monitoring are advised. The guidance provides details of an ongoing registry set up by the ISTH where physicians can submit data regarding cases of DOAC exposure during pregnancy. ${ }^{83}$ In breastfeeding women, both sets of guidelines advise against the use of DOACs due to a lack of evidence of their safety in this setting. ${ }^{83,84}$ The ASH guidelines suggest use of LMWH, warfarin, acenocoumarol, fondaparinux, UFH, or danaparoid during breastfeeding. Further clinical advice is provided around specific clinical scenarios and for subpopulations of female patients, for example, those with hereditary thrombophilia or who are undergoing androgen replacement therapy. ${ }^{84}$

Women aged $<60$ years who received rivaroxaban in the EINSTEIN DVT and EINSTEIN PE studies had a higher risk of uterine bleeding than those who received enoxaparin/VKA therapy (29.8 vs. $15.5 \% /$ year in patients with hormonal therapy and 30.7 vs. $13.4 \%$ year in patients without hormonal therapy; adjusted HR: $2.13,95 \%$ CI: $1.57-2.89) .{ }^{85}$ In a post hoc analysis of the Hokusai-VTE trial, edoxaban was associated with a higher rate of abnormal vaginal bleeding compared with warfarin in women aged $<50$ years ( 15 vs. $9 \% /$ year; HR: $1.7,95 \% \mathrm{CI}: 1.1-2.5){ }^{86}$ Furthermore, an analysis of data collected from female patients in the AMPLIFY trial indicated that the relative occurrence of vaginal bleeding events was higher in the apixaban group compared with the enoxaparin/warfarin group; CRNM vaginal bleeding occurred in 2.5 and $2.1 \%$ of women, respectively (OR: 1.2 , 95\% CI: $0.67-2.0) .{ }^{87}$

\section{Selecting Patients Suitable for Extended Venous Thromboembolism Treatment}

The risk of recurrent VTE has been shown to persist for at least 10 years despite the use of acute-phase anticoagulation ${ }^{88}$; the optimum treatment goal is to prescribe anticoagulation therapy for as long as necessary and for as short as possible to manage the respective risks of VTE recurrence and bleeding. The 2016 update of the ACCP guidelines recommends 3 months' anticoagulation for VTE provoked by surgery, and extended therapy ( $>3$ months) in patients with CAT or with unprovoked proximal DVT or PE dependent on the bleeding risk. ${ }^{1}$ Apixaban, dabigatran, and rivaroxaban are all approved for extended secondary prevention of a recurrent VTE based on the placebo-controlled AMPLIFY-EXT, ${ }^{14}$ RE-SONATE, ${ }^{15}$ and EINSTEIN EXT ${ }^{12}$ trials, respectively; the VKA versus dabigatran extended-use trial, RE-MEDY ${ }^{15}$; and the acetylsalicylic acid (ASA) versus two doses of rivaroxaban for extended-use trial, EINSTEIN CHOICE. ${ }^{89}$ Efficacy and safety outcomes were largely consistent across patient subgroups in these trials.

-Fig. 1 provides an overview of approved DOAC dosing regimens for extended therapy, and it should be noted that a dose reduction for extended therapy applies for apixaban and rivaroxaban use. ${ }^{2,5}$ In AMPLIFY-EXT, two doses of apixaban (5 and $2.5 \mathrm{mg}$ b.i.d.) were compared with placebo, the apixaban $5 \mathrm{mg}$ b.i.d. dose known to be effective for the prevention of stroke and systemic embolism in patients with AF, and the apixaban $2.5 \mathrm{mg}$ b.i.d. dose being the lowest evaluated in phase II trials and effective for the prevention of VTE after major orthopaedic surgery. Compared with placebo, both doses were associated with a reduced risk of VTE, and bleeding risk was low and similar to that seen with placebo. ${ }^{14}$ For rivaroxaban, EINSTEIN CHOICE looked to provide a lower dose option for extended rivaroxaban use in patients at clinical equipoise for extended prevention of VTE recurrence this being (rivaroxaban $10 \mathrm{mg}$ o.d. vs. the earlier approved rivaroxaban $20 \mathrm{mg}$ o.d. dose), and ASA was the comparator. Both doses were superior to ASA for the extended prevention of recurrent VTE, with a similar risk of major bleeding $(<1 \%)$ and CRNM bleeding. ${ }^{89}$ This was consistent with previous studies that demonstrated that although ASA might reduce the risk of VTE recurrence compared with placebo (as demonstrated in the WARFASA trial, but not the ASPIRE trial), ${ }^{90,91}$ rivaroxaban was associated with a greater relative risk reduction versus placebo. EINSTEIN CHOICE provides a head-to-head validation of superior rivaroxaban efficacy and similar bleeding risk compared with ASA ${ }^{89}$ Of relevance to special populations, the risk of recurrent VTE was consistently lower with both doses of rivaroxaban therapy versus ASA across subgroups including age group, body weight and those with normal renal function or mild renal impairment. Of note, the possibility to reduce the rivaroxaban 20 to $15 \mathrm{mg}$ o.d. dose for patients with $\mathrm{CrCl}$ between 15 and $49 \mathrm{~mL} / \mathrm{min}$ still applied. ${ }^{5}$ The risk of major bleeding and CRNM bleeding was favorable toward rivaroxaban use in patients aged $>75$ years, with a history of VTE and classed as fragile. ${ }^{89}$

A new data analysis of EINSTEIN EXT and EINSTEIN CHOICE supported the use of extended therapy in patients 
with unprovoked VTE (as already established), and suggested that patients with minor transient (e.g., immobilization) or minor persistent risk factors (e.g., $B M I>30 \mathrm{~kg} / \mathrm{m}^{2}$, $\mathrm{CrCl}<50 \mathrm{~mL} / \mathrm{min}$, congestive heart failure) might also benefit from extended therapy. ${ }^{92}$

\section{Conclusion}

The approval of DOACs following their respective VTE phase III treatment studies has provided physicians with effective and safe oral anticoagulation options with fewer burdens than traditional therapies such as VKAs and parenteral agents, which is reflected in their widespread uptake into clinical practice. Furthermore, subanalyses of the phase III studies in patients with comorbidities such as renal impairment, and specific studies in key patient groups such as those with cancer, have further supported the use of the DOACs in a broad range of patients with VTE. Despite this, and the incorporation of these findings into guidelines as they evolve, many important clinical questions exist regarding the use of DOACs in this setting. This review has discussed many of these queries, including DOAC suitability, dose and duration of treatment across important patient groups, as well as identifying gaps in current knowledge. Ongoing research has also been highlighted, and these efforts will contribute greatly to illuminating our understanding of VTE management and continuing to refine the management of all patients with VTE.

\section{Conflict of Interest}

C.E.K. reports personal fees from Bayer Health Care, Boehringer Ingelheim, Bristol Myers Squibb, Daiichi Sankyo, and Pfizer Pharma during the conduct of the study; personal fees from Amgen and Sanofi-Aventis outside the submitted work. S.M. reports grants and personal fees from Aspen, Bayer, BMS/Pfizer, Boehringer Ingelheim, Daiichi Sankyo, GSK, Portola, Sanquin, and Sanofi during the conduct of the study.

\section{Acknowledgments}

The authors would like to acknowledge Hayley Dawson, who provided editorial support with funding from Bayer AG and Janssen Scientific Affairs, LLC.

\section{References}

1 Kearon C, Akl EA, Ornelas J, et al. Antithrombotic therapy for VTE disease: CHEST guideline and expert panel report. Chest 2016; 149(02):315-352

2 Bristol-Myers Squibb. Pfizer. Eliquis ${ }^{\circledR}$ (apixaban)Summary of Product Characteristics. 2019. Available at: http://www.ema.europa.eu/docs/ en_GB/document_library/EPAR_-_Product_Information/human/ 002148/WC500107728.pdf. Accessed December 24, 2019

3 Boehringer Ingelheim International GmbH. Pradaxa ${ }^{\circledR}$ (dabigatran etexilate) Summary of Product Characteristics. 2019. Available at: http://www.ema.europa.eu/docs/en_GB/document_library/EPAR _-_Product_Information/human/000829/WC500041059.pdf. Accessed August 29, 2019

4 Daiichi Sankyo Europe Gmb H. Lixiana ${ }^{\circledR}$ (edoxaban) Summary of Product Characteristics. 2019. Available at: http://www.ema.europa. eu/docs/en_GB/document_library/EPAR__Product_Information/ human/002629/WC500189045.pdf. Accessed December 24, 2019
5 Bayer AG. Xarelto ${ }^{\circledR}$ (rivaroxaban) Summary of Product Characteristics. 2019. Available at: https://www.ema.europa.eu/documents/ product-information/xarelto-epar-product-information_en.pdf. Accessed December 24, 2019

6 Ageno W, Haas S, Weitz JI, et al; GARFIELD-VTE investigators. Characteristics and management of patients with venous thromboembolism: The GARFIELD-VTE registry. Thromb Haemost 2019;119(02):319-327

7 Konstantinides SV, Meyer G, Becattini C, et al. ESC guidelines for the diagnosis and management of acute pulmonary embolism developed in collaboration with the European Respiratory Society (ERS). Eur Heart J 2020;41(4):543-603

8 Agnelli G, Buller HR, Cohen A, et al; AMPLIFY Investigators. Oral apixaban for the treatment of acute venous thromboembolism. $\mathrm{N}$ Engl J Med 2013;369(09):799-808

9 Schulman S, Kearon C, Kakkar AK, et al; RE-COVER Study Group. Dabigatran versus warfarin in the treatment of acute venous thromboembolism. N Engl J Med 2009;361(24):2342-2352

10 Schulman S, Kakkar AK, Goldhaber SZ, et al; RE-COVER II Trial Investigators. Treatment of acute venous thromboembolism with dabigatran or warfarin and pooled analysis. Circulation 2014;129 (07):764-772

11 Büller HR, Décousus H, Grosso MA, et al; Hokusai-VTE Investigators. Edoxaban versus warfarin for the treatment of symptomatic venous thromboembolism. N Engl J Med 2013;369(15):1406-1415

12 Bauersachs R, Berkowitz SD, Brenner B, et al; EINSTEIN Investigators. Oral rivaroxaban for symptomatic venous thromboembolism. N Engl J Med 2010;363(26):2499-2510

13 Büller HR, Prins MH, Lensin AW, et al; EINSTEIN-PE Investigators. Oral rivaroxaban for the treatment of symptomatic pulmonary embolism. N Engl J Med 2012;366(14):1287-1297

14 Agnelli G, Buller HR, Cohen A, et al; AMPLIFY-EXT Investigators. Apixaban for extended treatment of venous thromboembolism. N Engl J Med 2013;368(08):699-708

15 Schulman S, Kearon C, Kakkar AK, et al; RE-MEDY Trial Investigators; RE-SONATE Trial Investigators. Extended use of dabigatran, warfarin, or placebo in venous thromboembolism. N Engl J Med 2013;368(08):709-718

16 Paravattil B, Elewa H. Approaches to direct oral anticoagulant selection in practice. J Cardiovasc Pharmacol Ther 2018; 24:1074248418793137

17 Portola Pharmaceuticals Inc. BEVYXXA ${ }^{\circledR}$ (betrixaban) Prescribing Information. 2017. Available at: https://www.bevyxxa.com/wp-content/uploads/2017/11/bevyxxa-betrixaban-capsules-prescribinginformation-pdf. Accessed August 12, 2019

18 Tsiara S, Pappas K, Boutsis D, Laffan M. New oral anticoagulants: should they replace heparins and warfarin? Hellenic J Cardiol 2011;52(01):52-67

19 Bristol-Myers Squibb. Coumadin (warfarin sodium) Prescribing Information. 2017. Available at: http://packageinserts.bms.com/pi/pi_coumadin.pdf. Accessed August 12, 2019

20 Wang Y, Bajorek B. New oral anticoagulants in practice: pharmacological and practical considerations. Am J Cardiovasc Drugs 2014;14(03):175-189

21 Douketis JD, Spyropoulos AC, Duncan J, et al. Perioperative management of patients with atrial fibrillation receiving a direct oral anticoagulant. JAMA Intern Med 2019;179(11):1469-1478

22 Burnett AE, Mahan CE, Vazquez SR, Oertel LB, Garcia DA, Ansell J. Guidance for the practical management of the direct oral anticoagulants (DOACs) in VTE treatment. J Thromb Thrombolysis 2016;41(01):206-232

23 van Es N, Coppens M, Schulman S, Middeldorp S, Büller HR. Direct oral anticoagulants compared with vitamin $\mathrm{K}$ antagonists for acute venous thromboembolism: evidence from phase 3 trials. Blood 2014;124(12):1968-1975

24 Ageno W, Mantovani LG, Haas S, et al. Safety and effectiveness of oral rivaroxaban versus standard anticoagulation for the treatment of symptomatic deep-vein thrombosis (XALIA): an 
international, prospective, non-interventional study. Lancet Haematol 2016;3(01):e12-e21

25 Boehringer Ingelheim International GmbH. Praxbind ${ }^{\circledR}$ (idarucizumab) Summary of Product Characteristics. 2018. Available at: http://www.ema.europa.eu/docs/en_GB/document_library/ EPAR_-_Product_Information/human/003986/WC500197462. pdf. Accessed December 12, 2019

26 Portola Pharmaceuticals Inc. ANDEXXA ${ }^{\circledR}$ (andexanet alfa) Prescribing Information. 2018. Available at: https://www.portola.com/wpcontent/uploads/Andexxa-prescribing-information-pdf.pdf. Accessed August 12, 2019

27 European Medicines Agency. Press release: First antidote for reversal of anticoagulation with factor Xa inhibitors apixaban and rivaroxaban. 2019. Available at: https://www.ema.europa.eu/en/news/first-antidote-reversal-anticoagulation-factor-xainhibitors-apixaban-rivaroxaban. Accessed August 12, 2019

28 Böttger B, Wehling M, Bauersachs RM, et al. Prevalence of renal insufficiency in hospitalised patients with venous thromboembolic events: a retrospective analysis based on 6,725 VTE patients. Thromb Res 2014;134(05):1014-1019

29 Gremmel T, Niessner A, Domanovits $H$, et al. Non-vitamin $\mathrm{K}$ antagonist oral anticoagulants in patients with an increased risk of bleeding. Wien Klin Wochenschr 2018;130(23-24):722-734

30 Ocak G, Lijfering WM, Verduijn M, et al. Risk of venous thrombosis in patients with chronic kidney disease: identification of highrisk groups. J Thromb Haemost 2013;11(04):627-633

31 Bauersachs RM, Lensing AWA, Prins MH, et al. Rivaroxaban versus enoxaparin/vitamin K antagonist therapy in patients with venous thromboembolism and renal impairment. Thromb J 2014; $12: 25-32$

32 Monreal M, Falgá C, Valle R, et al; RIETE Investigators. Venous thromboembolism in patients with renal insufficiency: findings from the RIETE Registry. Am J Med 2006;119(12):1073-1079

33 Goldhaber SZ, Schulman S, Eriksson H, et al. Dabigatran versus warfarin for acute venous thromboembolism in elderly or impaired renal function patients: pooled analysis of RE-COVER and RE-COVER II. Thromb Haemost 2017;117(11):2045-2052

34 Geldhof V, Vandenbriele C, Verhamme P, Vanassche T. Venous thromboembolism in the elderly: efficacy and safety of non-VKA oral anticoagulants. Thromb J 2014;12:21

35 Turpie AGG, Purdham D, Ciaccia A. Nonvitamin K antagonist oral anticoagulant use in patients with renal impairment. Ther Adv Cardiovasc Dis 2017;11(09):243-256

36 Lutz J, Jurk K, Schinzel H. Direct oral anticoagulants in patients with chronic kidney disease: patient selection and special considerations. Int J Nephrol Renovasc Dis 2017;10:135-143

37 Posch F, Ay C, Stöger H, Kreutz R, Beyer-Westendorf J. Exposure to vitamin $\mathrm{k}$ antagonists and kidney function decline in patients with atrial fibrillation and chronic kidney disease. Res Pract Thromb Haemost 2019;3(02):207-216

38 Key NS, Khorana AA, Kuderer NM, et al. Venous thromboembolism prophylaxis and treatment in patients with cancer: ASCO clinical practice guideline update. J Clin Oncol 2020;38(5):496-520

39 Farge D, Frere C, Connors JM, et al; International Initiative on Thrombosis and Cancer (ITAC) advisory panel. 2019 international clinical practice guidelines for the treatment and prophylaxis of venous thromboembolism in patients with cancer. Lancet Oncol 2019;20(10):e566-e581

40 Meyer G, Marjanovic Z, Valcke J, et al. Comparison of lowmolecular-weight heparin and warfarin for the secondary prevention of venous thromboembolism in patients with cancer: a randomized controlled study. Arch Intern Med 2002;162(15): $1729-1735$

41 Lee AY, Levine MN, Baker RI, et al; Randomized Comparison of Low-Molecular-Weight Heparin versus Oral Anticoagulant Therapy for the Prevention of Recurrent Venous Thromboembolism in Patients with Cancer (CLOT) Investigators. Low-molecular-weight heparin versus a coumarin for the prevention of recurrent venous thromboembolism in patients with cancer. N Engl J Med 2003;349 (02):146-153

42 Deitcher SR, Kessler CM, Merli G, Rigas JR, Lyons RM, Fareed J; ONCENOX Investigators. Secondary prevention of venous thromboembolic events in patients with active cancer: enoxaparin alone versus initial enoxaparin followed by warfarin for a 180day period. Clin Appl Thromb Hemost 2006;12(04):389-396

43 Hull RD, Pineo GF, Brant RF, et al; LITE Trial Investigators. Selfmanaged long-term low-molecular-weight heparin therapy: the balance of benefits and harms. Am J Med 2007;120(01):72-82

44 Mantha S, Miao Y, Wills J, Parameswaran R, Soff GA. Enoxaparin dose reduction for thrombocytopenia in patients with cancer: a quality assessment study. J Thromb Thrombolysis 2017;43(04):514-518

45 Imberti D, Cimminiello C, Di Nisio M, Marietta M, Polo Friz H, Ageno W. Antithrombotic therapy for venous thromboembolism in patients with cancer: expert guidance. Expert Opin Pharmacother 2018;19(11):1177-1185

46 Khorana AA, Yannicelli D, McCrae KR, et al. Evaluation of US prescription patterns: Are treatment guidelines for cancer-associated venous thromboembolism being followed? Thromb Res 2016;145:51-53

47 Khorana A, McCrae K, Milentijevic D, et al. Anticoagulant treatment patterns for cancer-associated thrombosis in a commercial insurance population. Circulation 2017:136 Abstract 15539

48 Khorana AA, McCrae KR, Milentijevic D, et al. Current practice patterns and patient persistence with anticoagulant treatments for cancer-associated thrombosis. Res Pract Thromb Haemost 2017;1(01):14-22

49 Raskob GE, van Es N, Verhamme P, et al; Hokusai VTE Cancer Investigators. Edoxaban for the treatment of cancer-associated venous thromboembolism. N Engl J Med 2018;378(07):615-624

50 Di Nisio M, van Es N, Carrier M, et al. Extended treatment with edoxaban in cancer patients with venous thromboembolism: A post-hoc analysis of the Hokusai-VTE Cancer study. J Thromb Haemost 2019;17(11):1866-1874

51 Young AM, Marshall A, Thirlwall J, et al. Comparison of an oral Factor Xa inhibitor with low molecular weight heparin in patients with cancer with venous thromboembolism: results of a randomized trial (SELECT-D). J Clin Oncol 2018;36(20):2017-2023

52 McBane RD II, Wysokinski WE, Le-Rademacher JG, et al. Apixaban and dalteparin in active malignancy-associated venous thromboembolism: the ADAM VTE trial. J Thromb Haemost 2020;18(02): 411-421

53 Khorana AA, Noble S, Lee AYY, et al. Role of direct oral anticoagulants in the treatment of cancer-associated venous thromboembolism: guidance from the SSC of the ISTH. J Thromb Haemost 2018;16(09):1891-1894

54 National Comprehensive Cancer Network. Cancer-associated venous thromboembolic disease, version 1.2019. Plymouth Meeting, PA, USA: National Comprehensive Cancer Network, Inc. 2019. Available at: https://www.nccn.org/professionals/physician_gls/pdf/vte.pdf. Accessed August 12, 2019

55 Cohen AT, Maraveyas A, Beyer-Westendorf J, et al. Patientreported outcomes associated with switching to rivaroxaban for the treatment of venous thromboembolism (VTE) in patients with active cancer. Ann Oncol 2019;30:v724-725

56 Picker N, Cohen AT, Maraveyas A, et al. Patient preferences regarding anticoagulation therapy in patients with cancer having a VTE event - a Discrete Choice Experiment in the COSIMO study. Blood 2019;134(Suppl 1):2159

57 Agnelli G, Becattini C, Bauersachs R, et al; Caravaggio Study Investigators. Apixaban versus dalteparin for the treatment of acute venous thromboembolism in patients with cancer: the Caravaggio study. Thromb Haemost 2018;118(09):1668-1678

58 Assistance Publique - Hôpitaux de Paris. Cancer associated thrombosis, a pilot treatment study using rivaroxaban (CASTA-DIVA). 2018. Available at: https://clinicaltrials.gov/ct2/show/NCT02746185. Accessed August 12, 2019 
59 AIO-Studien-gGmbH. Rivaroxaban in the treatment of venous thromboembolism (VTE) in cancer patients. 2018. Available at: https://clinicaltrials.gov/ct2/show/study/NCT02583191. Accessed August 12, 2019

60 Khorana AA, Soff GA, Kakkar AK, et al; CASSINI Investigators. Rivaroxaban for thromboprophylaxis in high-risk ambulatory patients with cancer. N Engl J Med 2019;380(08):720-728

61 Carrier M, Abou-Nassar K, Mallick R, et al; AVERT Investigators. Apixaban to prevent venous thromboembolism in patients with cancer. N Engl J Med 2019;380(08):711-719

62 Cohen AT, Gitt AK, Bauersachs R, et al. The management of acute venous thromboembolism in clinical practice. Results from the European PREFER in VTE Registry. Thromb Haemost 2017;117 (07):1326-1337

63 Ageno W, Becattini C, Brighton T, Selby R, Kamphuisen PW. Cardiovascular risk factors and venous thromboembolism: a meta-analysis. Circulation 2008;117(01):93-102

64 Shariff N, Aleem A, Levin V, et al. Venous thromboembolism in patients with heart failure: in-hospital and chronic use of anticoagulants for prevention. Recent Pat Cardiovasc Drug Discov 2012;7(01):53-58

65 Prins MH, Lensing AWA, Bauersachs R, et al; EINSTEIN Investigators. Oral rivaroxaban versus standard therapy for the treatment of symptomatic venous thromboembolism: a pooled analysis of the EINSTEIN-DVT and PE randomized studies. Thromb J2013;11(01):21

66 Vanassche T, Verhamme P, Wells PS, et al. Impact of age, comorbidity, and polypharmacy on the efficacy and safety of edoxaban for the treatment of venous thromboembolism: An analysis of the randomized, double-blind Hokusai-VTE trial. Thromb Res 2018; 162:7-14

67 von Vajna E, Alam R, So TY. Current clinical trials on the use of direct oral anticoagulants in the pediatric population. Cardiol Ther 2016;5(01):19-41

68 Monagle P, Chan AKC, Goldenberg NA, et al. Antithrombotic therapy in neonates and children: antithrombotic therapy and prevention of thrombosis, 9th ed: American College of Chest Physicians evidence-based clinical practice guidelines. Chest 2012;141(02):e737S-e801S

69 Jaffray J, Young G. Deep vein thrombosis in pediatric patients. Pediatr Blood Cancer 2018;65(03):e26881

70 Halton JM, Lehr T, Cronin L, et al. Safety, tolerability and clinical pharmacology of dabigatran etexilate in adolescents. An openlabel phase Ila study. Thromb Haemost 2016;116(03):461-471

71 Halton JML, Albisetti M, Biss B, et al. Phase Ila study of dabigatran etexilate in children with venous thrombosis: pharmacokinetics, safety, and tolerability. J Thromb Haemost 2017;15(11):2147-2157

72 Halton JML, Picard AC, Harper R, et al. Pharmacokinetics, pharmacodynamics, safety and tolerability of dabigatran etexilate oral liquid formulation in infants with venous thromboembolism. Thromb Haemost 2017;117(11):2168-2175

73 Monagle P, Lensing AWA, Thelen K, et al; EINSTEIN-Jr Phase 2 Investigators. Bodyweight-adjusted rivaroxaban for children with venous thromboembolism (EINSTEIN-Jr): results from three multicentre, single-arm, phase 2 studies. Lancet Haematol 2019;6(10):e500-e509

74 Albisetti M, Biss B, Bomgaars L, et al. Design and rationale for the DIVERSITY study: an open-label, randomized study of dabigatran etexilate for pediatric venous thromboembolism. Res Pract Thromb Haemost 2018;2(02):347-356

75 Albisetti M, Brandão L, Bomgaars L, et al. Efficacy and safety of dabigatran etexilate for treatment of venous thromboemboism in paediatric patients: results of the DIVERSITY trial. ISTH Congress. Melbourne, Australia, 6-10 July 2019, Abstract OC 57.3. Available at: https://www.cochranelibrary.com/central/doi/10.1002/central/CN-01968246/full. Accessed April 13, 2020

76 Luciani M, Albisetti M, Biss B, et al. Phase 3, single-arm, multicenter study of dabigatran etexilate for secondary prevention of venous thromboembolism in children: Rationale and design. Res Pract Thromb Haemost 2018;2(03):580-590

77 Brandão L, Albisetti M, Halton J, et al. Safety of dabigatran etexilate for the secondary prevention of venous thromboembolism in children. Blood 2020;135(7):491-504

78 Bayer, Janssen Research \& Development LLC. EINSTEIN Junior: oral rivaroxaban in children with venous thrombosis (EINSTEIN Jr). 2018. Available at: https://clinicaltrials.gov/ct2/show/NCT02234843. Accessed August 12, 2019

79 Male C, Lensing AWA, Kubitza D, et al. Rivaroxaban for the treatment of acute venous thromboembolism in children. ISTH Congress. Melbourne, Australia, 6-10 July 2019, Abstract LB 01.5. Available at: https://isthcongressdaily.org/rivaroxaban-for-thetreatment-of-acute-venous-thromboembolism-in-children/. Accessed April 13, 2020

80 Pfizer B-MS. Apixaban for the acute treatment of venous thromboembolism in children. 2019. Available at: https://clinicaltrials. gov/ct2/show/NCT02464969. Accessed August 27, 2019

81 Daiichi Sankyo Inc. Phase 1 pediatric pharmacokinetics/pharmaco dynamics (PK/PD) study. 2019. Available at: https://clinicaltrials.gov/ ct2/show/NCT02303431. Accessed August 12, 2019

82 Daiichi Sankyo Inc. Hokusai study in pediatric patients with confirmed venous thromboembolism (VTE). 2019. Available at: https://clinicaltrials.gov/ct2/show/study/NCT02798471. Accessed August 27, 2019

83 Gibson CM, Mehran R, Bode C, et al. Prevention of bleeding in patients with atrial fibrillation undergoing PCI. N Engl J Med 2016;375(25):2423-2434

84 Bates SM, Rajasekhar A, Middeldorp S, et al. American Society of Hematology 2018 guidelines for management of venous thromboembolism: venous thromboembolism in the context of pregnancy. Blood Adv 2018;2(22):3317-3359

85 Martinelli I, Lensing AWA, Middeldorp S, et al. Recurrent venous thromboembolism and abnormal uterine bleeding with anticoagulant and hormone therapy use. Blood 2016;127(11):1417-1425

86 Scheres LJJ, Bistervels IM, Middeldorp S. Everything the clinician needs to know about evidence-based anticoagulation in pregnancy. Blood Rev 2019;33:82-97

87 Brekelmans MP, Scheres LJ, Bleker SM, et al. Abnormal vaginal bleeding in women with venous thromboembolism treated with apixaban or warfarin. Thromb Haemost 2017;117(04):809-815

88 Prandoni P, Noventa F, Ghirarduzzi A, et al. The risk of recurrent venous thromboembolism after discontinuing anticoagulation in patients with acute proximal deep vein thrombosis or pulmonary embolism. A prospective cohort study in 1,626 patients. Haematologica 2007;92(02):199-205

89 Weitz JI, Lensing AWA, Prins MH, et al; EINSTEIN CHOICE Investigators. Rivaroxaban or aspirin for extended treatment of venous thromboembolism. N Engl J Med 2017;376(13):1211-1222

90 Becattini C, Agnelli G, Schenone A, et al; WARFASA Investigators. Aspirin for preventing the recurrence of venous thromboembolism. N Engl J Med 2012;366(21):1959-1967

91 Brighton TA, Eikelboom JW, Mann K, et al; ASPIRE Investigators. Low-dose aspirin for preventing recurrent venous thromboembolism. N Engl J Med 2012;367(21):1979-1987

92 Prandoni P, Lensing AWA, Prins MH, et al. Benefits and risks of extended treatment of venous thromboembolism with rivaroxaban or with aspirin. Thromb Res 2018;168:121-129 